\title{
USING OF ALPHA LATTICE DESIGN FOR INCREASING PRECISION OF FABA BEAN YIELD TRIALS
}

\author{
Mona, Ismail ${ }^{(1)}$; Nemat, A. Noureldin ${ }^{(2)}$; Hany. S. Saudy ${ }^{(2)}$ \\ Manal, M. Mohamed ${ }^{(2)}$ and W. M. Fares ${ }^{(1)}$ \\ 1) Central Lab for Designing \& Statistical Analysis Researches, A.R.C \\ 2) Faculty of Agriculture, Ain Shams University
}

\begin{abstract}
The current investigation aimed at evaluating the yielding performance for 20 faba bean genotypes using randomized complete block design (RCBD) and alpha lattice design. The field experiments were conducted using alpha lattice design with three replications at Giza Agricultural Research Station during the two growing seasons of 2015/2016 and 2016/2017. Four statistical criteria being Coefficient of Variation (CV), Relative Efficiency (RE), Pvalue and power function were used to investigate the validity and usefulness of alpha lattice design over RCBD in accounting for the spatial variability. Results showed that alpha lattice design was more precise and effective in reducing the experimental error compared to RCBD indicating its great ability to detect the significance of small differences among genotypes means. The superiority of alpha lattice design over RCBD was clear in both seasons because they recorded the lowest values of each of CV and P-value beside the highest values of RE and power function. There was inconsistency in the rank orders of the genotype means resulted from alpha lattice design compared to RCBD. This result might be expected due to the different mathematical background of the two designs in removing plot to plot heterogeneity. Considering RCBD and alpha lattice designs simultaneously, results showed that genotypes number 6,8 and 10 produced the highest seed yields in the 1 st growing season with no significant differences among them while in the 2nd season, genotypes number 5, 9, 10 and 16 had the maximum seed yield.

Key words: faba bean, alpha lattice, relative efficiency, precision.
\end{abstract}




\section{INTRODUCTION}

Faba bean (Vicia faba L.) is still the corner stone of the legume crops grown in Egypt. It is an important source of high quality and inexpensive protein supplement for the majority of the Egyptian population. Also, it is known as an efficient atmospheric nitrogen fixer depending on availability of Rhizobium spp. that colonizes the legume plants which keeping the Egyptian soil fertile and benefits the subsequent crop. In Egypt, the demand for faba bean seed for food and feed purposes is increasing yearly.

Developing high yielding faba bean cultivars with improved seed quality is the back bone of any plan to enhance the local faba bean production. A good faba bean cultivar comes through evaluation of a large number of promising breeding materials at different levels of yield trials. When a large items is included in one replicate (as randomized complete block design), the replication size would increase and soil heterogeneity might exist and aggravate within it. To conduct an efficient variety trial, the experimental error must be controlled by choosing an appropriate experimental design or by using effective statistical analysis.

Therefore, an incomplete block design such as alpha lattice design (Patterson and Williams, 1976) might be considered a good alternative choice for RCBD. Patterson et al. (1978), Patterson and Hunter (1983), Yau (1997), Masood et al. (2007 and 2008), Kashif et al. (2011 a and b), Abdel Mohsen and Abo-Hegazy (2013) and Abdel-Shafi (2014) used alpha lattice design in their field trials on different crops and concluded that this design appeared to be a more powerful tool in controlling experimental error than RCBD. 
Alpha lattice design (sometimes called generalized lattice design) is an important version of incomplete block designs group (IBD) that could reduce the experimental error by extracting out the variability among small blocks, thereby, minimizing the unknown variation within each replication, consequently improving the efficiency of field trial compared to RCBD (Kashif et al., $2011 \mathrm{a}$ and b).

Although, alpha lattice design gives more precise results, it was rarely used in designing and analyzing the yield trials in Egypt. The main purpose of this research was to determine the validity and usefulness of using alpha lattice design over RCBD in identifying the promising genotypes in faba bean yield trials.

\section{MATERIALS AND METHODS}

A field experiment was conducted at the Experimental Farm of Giza Agricultural Research Station, during the two successive seasons of $2015 / 2016$ and $2016 / 2017$ to evaluate the yielding ability of 20 faba bean genotypes. The tested genotypes (denoted as G1 to G20) comprised three Egyptian commercial cultivars (Nubaria1, Sakha 3 and Giza 834), in addition to 17 genotypes imported from International Center for Agricultural Research in Dry Areas (ICARDA). The pedigree of tested genotypes is presented in Table (1). 
Table (1): Pedigree of the tested faba bean genotypes

\begin{tabular}{|c|c|c|}
\hline Code no. & Genotype & Pedigree \\
\hline \hline G1 & Hudeiba 93 & ILB1270XSel.2008 latt629 \\
\hline G2 & S2009,00100 & SelF7/8975/05XSel.2007latt7025 \\
\hline G3 & 33103 & HBP/SOD/2000 \\
\hline G4 & 3314 & HBP/SOD/2000 \\
\hline G5 & Wadi1 & Wadi1 \\
\hline G6 & S 2008, 021 & F5 (F7/8990/05 X sel2004latt.47-1) THTRTR21-3 \\
\hline GHTRTR-21-3
\end{tabular}

Faba bean genotypes were laid out in an alpha lattice design with three replications as described by Patterson and Williams (1976). Each replication was divided into five incomplete blocks with four plots each. The layout of 
the field experiment was a grid of 15 rows and 4 columns in the two growing seasons as shown in table. (1).

Table (2): The arrangement allocation of 20 genotypes as layout by alpha lattice design (three replications with five blocks of four plots each)

\begin{tabular}{|c|c|c|c|c|c|}
\hline Replication & Block & 1 & 2 & 3 & 4 \\
\hline \multirow{5}{*}{ (1) } & 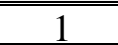 & 11 & 7 & 88 & 10 \\
\hline & 2 & 17 & 4 & 9 & 1 \\
\hline & 3 & 5 & 20 & 2 & 16 \\
\hline & 4 & 19 & 13 & 6 & 15 \\
\hline & 5 & 12 & 14 & 3 & 18 \\
\hline \multirow{5}{*}{ (2) } & 1 & 3 & 5 & 4 & 15 \\
\hline & 2 & 6 & 17 & 16 & 8 \\
\hline & 3 & 7 & 18 & 9 & 19 \\
\hline & 4 & 11 & 12 & 13 & 2 \\
\hline & 5 & 20 & 1 & 10 & 14 \\
\hline \multirow{5}{*}{ (3) } & 1 & 15 & 20 & 8 & 18 \\
\hline & 2 & 17 & 2 & 3 & 7 \\
\hline & 3 & 12 & 10 & 4 & 6 \\
\hline & 4 & 13 & 14 & 16 & 9 \\
\hline & 5 & 19 & 5 & 11 & 1 \\
\hline
\end{tabular}

Each plot consisted of three ridges of four $\mathrm{m}$ long and $0.6 \mathrm{~m}$ apart (plot area $=7.2 \mathrm{~m}^{2}$ ) with two seeds/hill, $20 \mathrm{~cm}$ apart. All other agricultural practices were maintained at optimum levels to maximize faba bean productivity. At maturity, each plot were harvested to determine the seed yield in kilograms per plot and converted to the unit of ardab/feddan (one faddan $=4200 \mathrm{~m}^{2}$ ).

Statistical analysis: Alpha lattice designs are partially balanced designs because some pairs of genotypes did not meet in any incomplete block (termed as 0), other pairs of genotypes came together in the incomplete 
blocks once (termed as 1), others came together twice (termed as 2). Accordingly, there are many available orders of alpha lattice designs but the two orders of $(0,1)$ and $(0,1,2)$ are considered the most efficient and accurate structures. In the current work, the layout plan of the 20 tested genotypes followed the order of $(0,1)$.

Data of seed yield were firstly analyzed using the traditional model of RCBD (Cochran and Cox, 1957). Also, the appropriate alpha lattice model was used as developed by Patterson and Williams (1976). However, the valid standard error was used to estimate the least significant difference (LSD) to compare each pair-wise genotype means.

The statistical comparison among the used models of analysis was assessed on the basis of:

1- Coefficient of variation ( $\mathrm{CV} \%)$ which was calculated to compare the efficiency of the two models in reducing the experimental error variance.

2- Relative efficiency (RE \%) was used to assess the improvement in precision of alpha lattice design over RCBD. The values of RE\% were computed as a ratio between error variance of RCBD and that estimated from alpha lattice design. If the RE \% value is greater than one, then alpha lattice results in a smaller error variance and it adjusts the genotype means for plot to plot variability. When the RE \% is less than one, the alpha lattice are less efficient than RCBD. In this case, the trial is analyzed as RCBD and the genotype means are not adjusted. Since, error degrees of freedom for all used models of analysis were more than 20, their effects on $\mathrm{RE} \%$ are negligible. 
3- P-value for genotype source of variation was recorded to express Type I error.

4- The power function was estimated to know the ability of the used model to detect the significant differences among genotype means (Kirk, 1995).

In fact, the majority of researchers did not determine power function of their field experiments. They make their management decisions only on a Pvalue (Type I error). Glaz and Dean (1988) and Kirk (1995) mentioned that power function must be more than 0.80 for statistically acceptable precision.

Alpha lattice design call for an adjustment of genotype means to discard the effects of block which may disturb the genotype ranks compared to RCBD. Accordingly, estimates of adjusted genotype means and their ranks were compared using Spearman rank correlation coefficients to identify the effect of using RCBD and alpha lattice designs on the selection of elite genotypes (Browine et al., 1993; Fares et al., 2011; Hager, 2012 and Morsy and Fares, 2016).

\section{RESULTS AND DISCUSSION}

The analyses of variance for seed yield (ardab/fed) using RCBD and alpha lattice design of the growing seasons of 2015/2016 and 2016/2017 are presented in Table (3). Fitting RCBD model, the results showed that the genotype source of variation was only significant $(\mathrm{P}<0.05)$ in the first season. The replication effect was not significant in the two seasons. These results supported the fact that unknown variation did extended through the experimental fields (Kirk et al., 1980). Warren and Mendez (1982) indicated that blocks failed to account for intra-site heterogeneity when they were too 
large, poorly oriented, or had within block heterogeneity. The previous results confirmed the need for using other corrective design or analysis such as alpha lattice analysis which can give the desired precision.

Alpha lattice design recorded highly significant F-test for genotype effect in the two growing seasons. The significance of adjusted genotype effect may be due to the remarkable reduction of the error mean square (EMS) from 3.04 and 4.29 for RCBD to 1.85 and 2.17 for alpha design, in the two growing seasons, respectively. However, the highly significance of adjusted block term indicated that a considerable component of spatial variability may be found within the relatively large replication of RCBD (consisting of 20 plots each) which was then effectively removed by the smaller block size of alpha lattice design (consisting of only 4 plots each). These results are in accordance with the findings of Abdel-Mohsen and Abo-Hegazy (2013), Abdel-Shafi (2014), Fares et.al (2011) and Morsy and Fares (2016).

Table (3): Analysis of variance for seed yield (ardab/fed) using RCBD and alpha lattice design in 2015/2016 and 2016/2017 seasons

\begin{tabular}{|c|c|c|c|c|}
\hline \multirow{2}{*}{$\begin{array}{l}\text { Models of } \\
\text { analysis }\end{array}$} & \multirow{2}{*}{ Source of variation } & \multirow{2}{*}{ D. F. } & \multicolumn{2}{|c|}{ Mean square } \\
\hline & & & $2015 / 2016$ & $2016 / 2017$ \\
\hline \multirow{3}{*}{ RCBD } & Replications & 2 & 1.06 & 0.32 \\
\hline & Genotypes & 19 & $6.22 *$ & 7.12 \\
\hline & Error & 38 & 3.04 & 4.29 \\
\hline \multirow{4}{*}{$\begin{array}{c}\text { Alpha } \\
\text { Lattice Design }\end{array}$} & Replications & 2 & 1.06 & 0.32 \\
\hline & Blocks/Rep. (adj.) & 12 & $5.62 * *$ & $8.87 * *$ \\
\hline & Genotypes (adj.) & 19 & $6.94 * *$ & $9.54 * *$ \\
\hline & Error & 26 & 1.85 & 2.17 \\
\hline & Total & 59 & & \\
\hline
\end{tabular}

$(*)$ and $(* *)$ : Significant at 0.05 and 0.01 probability levels, respectively 
Patterson and Hunter (1983), and Yau (1997) reported that the incomplete block design (such as alpha lattice design) seems to be more effective with larger trails than those involving small numbers of entries. The present results agreed with those obtained by Pearce, (1978), Lin et al. (1993), Kempton et al. (1994) and Qiao et al. (2000).

In order to make the right decision about the statistically preferred model, results in Table (3) showed the comparison among the RCBD and alfa models using four statistical criteria being $\mathrm{CV} \%, \mathrm{RE} \%, \mathrm{P}$-value and power function. The model is statistically preferred when it recorded the highest value of $\mathrm{RE} \%$ and power function, along with acceptable low values of $\mathrm{CV} \%$ and $\mathrm{P}$ value.

Table (3) showed disappointing results when the RCBD was used due to the somewhat high estimates values of CV \% (17.06 and 20.11) in both seasons, respectively), indicating the presence of soil heterogeneity across the experimental area. In addition, insignificant P-value was recorded (0.09) for RCBD model in the second season compared to 0.03 in the first season. However, RCBD model recorded acceptable power function values $(>0.80)$ in the two seasons. The current results confirmed that the spatial heterogeneity in the field trials is a reality in spite of the use of replication and randomization in RCBD. Also, some uncontrolled factors can cause external damage to any field experiment and lead to intra-site variability which is not related to the replication position and cannot be controlled by them; even they were in the appropriate direction (Pearce, 1980). However, Lin et al. (1993) 
mentioned that the lack of choice for a proper orientation of replication layout is one of the factors that limit the successful use of RCBD.

Promising results were observed using alpha lattice design in the two seasons. Regarding to CV \% value, it reduced to 13.31 and 14.41 after using alpha lattice analysis, along with securing higher gain of relative efficiency over RCBD with 64.32 and $97.70 \%$, respectively. Also, there was a clear improvement in detecting differences among genotypes means since P-value dropped to 0.001 and 0.000 with alpha lattice analysis in the two seasons, respectively. As well as, power function values increased recording 0.99 in the two seasons indicating the great ability of this design to detect the small significant differences among genotype averages. Finally the current results concluded that the small blocks of alpha lattice structure were more homogenous compared to the larger area of the complete replication. Masood et al. (2007) mentioned that the small values of standard error of genotypic differences (SE diff) resulted from alpha lattice design helped to detect the significant smaller differences among genotypes means. Similar results were obtained by Yau (1997), Masood et al. (2008), Kashif et al. (2011)a, AbdelMohsen and Abo-Hegazy (2013), Abdel-Shafi (2014) and Morsy and Fares (2016). Table 3 estimation of CV\%, RE\%, P-value and power function for alpha lattice design compared to RCBD in 2015/2016 and 2016/2017 growing seasons. 
Table (4): The genotype averages of seed yield (ardab/fed) using RCBD and alpha lattice designs in both seasons

\begin{tabular}{|c|c|c|c|c|}
\hline \multirow{2}{*}{ Preference criteria } & \multicolumn{2}{|c|}{ 2015/2016 season } & \multicolumn{2}{c|}{ 2016/2017 season } \\
\cline { 2 - 5 } & RCBD & Alpha & RCBD & alpha \\
\hline \hline CV \% & 17.06 & 13.31 & 20.11 & 14.41 \\
\hline RE \% & 100 & 164.32 & 100 & 197.70 \\
\hline P- value & 0.03 & 0.001 & 0.09 & 0.000 \\
\hline Power function & 0.92 & 0.99 & 0.84 & 0.99 \\
\hline
\end{tabular}

Table (4) shows the genotype averages of seed yield (ardab/fed) using RCBD and alpha lattice designs in both seasons. Also, Table (4) contains the ranks of the highest yielding genotypes at a selection intensity of $20 \%$ (4 out of 20 genotypes).

Considering RCBD and alpha lattice designs simultaneously, results showed that genotypes number 6,8 and 10 produced the highest seed yields that ranged from 11.95 to $13.03 \mathrm{ardab} / \mathrm{fed}$ in the $1 \mathrm{st}$ growing season with no significant differences among them. While in the 2nd season, genotypes number 5, 9, 10 and 16 had the maximum seed yield that ranged from 13.10 to $13.99 \mathrm{ardab} / \mathrm{fed}$. The detected differences among the superior genotype ranks in the two growing seasons might be attributed to the environmental effects and their interaction with various genotypes. Accordingly, the previous elite genotypes should be taken into consideration by faba bean breeders. These results are in accordance with those obtained by Mohamed and Morsy (2005); Hamdi et al. (2008); Fares et al. (2011) and Morsy and Fares (2016). 
Table (5): Mean values of seed yield (ardab/fed) of faba bean genotypes estimated from RCBD and alpha lattice designs in 2015/2016 and 2016/2017 seasons

\begin{tabular}{|c|c|cc|cc|}
\hline \multirow{2}{*}{ Code } & \multirow{2}{*}{ Genotype } & \multicolumn{2}{|c|}{$\mathbf{2 0 1 5 / 2 0 1 6}$ season } & \multicolumn{2}{c|}{ 2016/2017 season } \\
\cline { 3 - 6 } & & RCBD & alpha & RCBD & Alpha \\
\hline G1 & Hudeiba 93 & 11.29 & 11.15 & 8.27 & 8.12 \\
\hline G2 & S2009,00100 & 8.52 & 6.78 & 8.39 & 7.93 \\
\hline G3 & 33103 & 11.48 & 11.32 & 8.18 & 7.38 \\
\hline G4 & 3314 & 9.24 & 8.51 & 11.06 & 9.51 \\
\hline G5 & Wadi 1 & 8.48 & 8.22 & 12.67 & $\underline{\mathbf{1 3 . 9 9}(\mathbf{1})}$ \\
\hline G6 & S 2008, 021 & $\underline{\mathbf{1 2 . 2 4}(\mathbf{1})}$ & $\underline{\mathbf{1 2 . 0 0}}$ & 9.36 & 9.45 \\
\hline G7 & 3320 & 11.71 & 11.88 & 10.50 & 9.25 \\
\hline G8 & Hudeiba 93 & $\underline{\mathbf{1 2 . 1 4}(\mathbf{2})}$ & $\underline{\mathbf{1 3 . 0 3}}$ & 10.76 & 10.12 \\
\hline G9 & S 2008, 057 & 10.71 & 11.01 & 12.27 & $\underline{\mathbf{1 3 . 2 8}(\mathbf{3})}$ \\
\hline G10 & 3321 & $\underline{\mathbf{1 1 . 9 5}(\mathbf{4})}$ & $\underline{\mathbf{1 1 . 9 7}}$ & 12.58 & $\underline{\mathbf{1 3 . 3 5}(\mathbf{2})}$ \\
\hline G11 & S02010,51 & 10.14 & 9.87 & 8.49 & 8.26 \\
\hline G12 & S2009,0091 & 9.57 & 8.37 & 8.41 & 7.45 \\
\hline G13 & S 2008, 057 & 8.91 & 9.18 & 9.85 & 11.29 \\
\hline G14 & S02010,51 & 8.38 & 9.11 & 9.76 & 10.03 \\
\hline G15 & S 2008, 061 & 8.67 & 10.18 & 9.85 & 8.58 \\
\hline G16 & 3312 & $\underline{\mathbf{1 2 . 0 0}(\mathbf{3})}$ & 11.66 & 11.52 & $\underline{\mathbf{1 3 . 1 0}(\mathbf{4})}$ \\
\hline G17 & S02010,157 & 8.62 & 7.51 & 12.42 & 10.73 \\
\hline G18 & Nubaria 1 & 10.95 & $\mathbf{1 2 . 0 2}$ & 11.82 & 12.01 \\
\hline G19 & Sakha 3 & 10.67 & 11.53 & 10.15 & 11.80 \\
\hline G20 & Giza 834 & 8.76 & 9.14 & 9.55 & 10.22 \\
\hline & LSD & $\mathbf{2 . 8 8}$ & $\mathbf{2 . 2 8}$ & NS & $\mathbf{2 . 4 7}$ \\
\hline
\end{tabular}

*Bold and underline cells refer to the highest 6 yielding genotypes and their ranks.

Spearman rank correlation coefficients were estimated among the genotype means that obtained by RCBD and alpha lattice designs in both seasons (Table 5). Results revealed positive and highly significant $(\mathrm{P}<0.01)$ Spearman correlation coefficients among the genotype means that obtained from the two designs in the $1^{\text {st }}$ season $\left(0.88^{* *}\right)$ and $2^{\text {nd }}$ season $(0.87 * *)$. 
The results cleared no perfect agreement (correlation coefficient $r \neq 1$ ) between the two designs in adjusting the genotype mean for spatial variability. This result might be attributed to the different mathematical background of the two designs in removing plot to plot heterogeneity. Already, there were upward and downward shifts in the genotype ranks under alpha lattice compared to RCBD. It is noted that the shift in genotype ranks might be related to the adjustments which made due to the patterns of intrasite variability across the field plots. A genotype might be ranked as the first one using $\mathrm{RCBD}$, but it is possible to downward recording a low rank order using alpha lattice after running the adjustment according to its position in the field map, and vice versa. Fares et al. (2011) and Morsy and Fares (2016) reported that the ranks of the tested genotypes were not constant using a simple square lattice design analysis compared to RCBD.

\section{Finally, the following conclusions may be stated:}

- The plot to plot variation in field trials is a reality in spite of using replication and randomization, as followed in the classical experimental designs (such as RCBD).

- In any field experiment, outside damage climatic conditions can lead to an intra-site heterogeneity which cannot be controlled by replications, even when they were in the appropriate orientation.

- When within replication variation is very small, the classical design RCBD would be satisfactory to verify a considerable level of precision and it is not necessary to use the alpha lattice design. 
- When the intra-site variability in a field trial is very complex, it is essential to use the alpha lattice design as an effective diagnostic and remedial tool.

- Application of alpha lattice design does not require major inputs or a complex field layout; therefore, it is proposed to use it in large variety trials.

- There are differences among the genotype mean values and their rank orders using alpha lattice compared to RCBD. This result is expected and could be related to the different mathematical background of the two used models.

\section{REFERENCES}

Abdel-Mohsen, A. A. and Abo-Hegazy, S. R. E. (2013): Comparing the relative efficiency of two experimental designs in wheat field trials. Egypt. J. Plant Breed. 17 (1): 1-17.

Abdel-Shafi, M. A. (2014): Efficiency of classical complete and incomplete block designs in yield trial on bread wheat genotypes. Research Journal of Agricultural and Biological Science. 10 (1): 17-23.

Browine, C.; Bowman, D. T. and Burton, J. W. (1993): Estimating spatial variation in analysis of data from yield trials: a comparison of methods . Agron. J., 85 : 1244-1253.

Cochran, W. G. and Cox, G. M. (1957): Experimental designs. $2^{\text {nd }}$ ed. John Wiley \& Sons, New York, USA.

Fares, W. M.; Fateh, H. S. A. and Morsy, A. R. (2011): Improving the precision of faba bean variety trials using trend analysis models. Egypt. J. Plant Breed. 15 (1): 103-116.

Glaz, B. and Dean, J. L. (1988): Statistical errors rates and their imolications in sugarcane clone trials. Agron. J., 80: 560-562. 
Hager, M. A. (2012): Using trend analysis models to improve efficiency of wheat (Triticum aestivum L.) variety trials. Bull. Fac. Agric., Cairo Univ., 63:252-260.

Hamdi, A.; Abdel-Mohsen M. I. and Mersal, I. F. (2008): Evaluation of some promising faba bean genotypes for agronomic and seed technology characteristics in North Egypt. Proceed. $2^{\text {nd }}$ Field Crops Conf., FCRI, ARC, Giza, Egypt, 14-16 Oct., 215-223.

Kashif, M.; Khan, M. I.; Arif, M.; Ahmad, M. and Mahmood, Kh. (2011 a): Experience in use alpha lattice design in Pakistan. International Journal of Intelligent Technologies and Applies Statistics. Vol. 4 (1): 133-146.

Kashif, M.; Khan, M. I.; Arif, M.; Anwer, M. and Ijaz, M. (2011 b): Efficiency of alpha lattice design in rice field trials in Pakistan. J. Sci. Res., 3 (1): 91-95.

Kempton, R. A.; Seraphin, J. C. and Sword, A. M. (1994): Statistical analysis of two dimensional variation in variety yield trials. J. Agric. Sci., 122: 335-342.

Kirk, H. J.; Haynes, F. L. and Monroe, R. J. (1980): Application of trend analysis to horticultural field trials. J. Amer. Soc. Hort. Sci., 105(2) : 189-193.

Kirk, R. E. (1995): Experimental design: procedures for the behavioral science (3rd Ed.), Pacific Grove, CA: Brooks/cole publishing.

Lin, C.S.; Binns, M. R.; Voldeg, H. D. and Guillemett, R. (1993): Performance of randomized block designs in field experiments. Agron. J., 85: 168-171.

Masood, M. A.; Farooq, K.; Mujahid, Y. and Anwar, M. Z. (2008): Improvement in precision of agricultural field experiments through design and analysis. Pakistan J. Life Soc. Sci., 6: 89-91.

Masood, M. A.; Malik, S. N.; Nazakat, N. and Abid, S. (2007): Blocks within replication improve experimental efficiency in preliminary yield trial on groundnut. Pakistan J. of Agric. Res., 20 (3-4):116-118. 
Mohamed, S. A. and Morsy, Faiza, M. (2005): Evaluation of some faba bean genotypes in the new reclaimed lands of east Owinat. J. Agric. Sci., Mansoura Univ., 30 (1): 79-89.

Morsy, A. R. and Fares, W. M. (2016): Utilization of alpha lattice design and trend analysis for controlling the experimental error in soybean variety trials. Alex. J. Agric. Sci., Vol. 61(4): 399-407.

Patterson, H. D. and Hunter, E. A. (1983): The efficiency of incomplete block designs in national list and recommended list cereal variety trials. J. Agric. Sci., Camb., 101(2): 427-433.

Patterson, H. D. and Williams, E. R. (1976): A new class of resolvable incomplete block designs. Biometrika, 63: 83-90.

Patterson, H. D.; Williams, E. R. and Hunter, E. A. (1978): Block designs for variety trials. J. Agric. Sci., Camb., 90 (2): 395-400.

Pearce, S. C. (1978): The control of environmental variation in some West Indian maize experiments. Trop. Agric. (Trinidad), 55: 97-106.

Pearce, S. C. (1980): Randomized blocks and some alternatives: a study in tropical conditions. Trop. Agric. (Trinidad), 57: 1-10.

Qiao, C. G.; Basford, K. E.; Delay, I. H. and Cooper, M. (2000): Evaluation of experimental designs and spatial analysis in wheat breeding trials. Theor. Appl. Genet., 100: 9-16.

Warren, J. A. and Mendez, I. (1982): Methods for estimating background variation in field experiments. Agron. J., 74: 1004-1009.

Yau, S. K. (1997): Efficiency of alpha-lattice designs in international variety yield trials of barley and wheat. J. of Agric. Sci., Camb., 128: 5-9. 


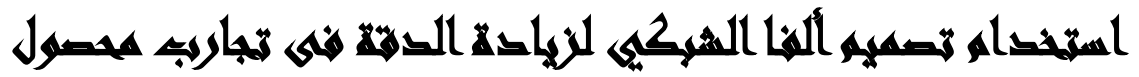 الهول اللهلكين}

[0]

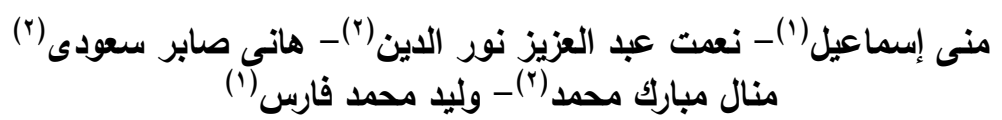

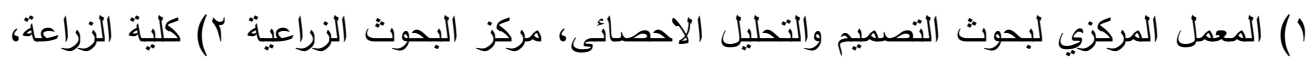

جامعة عين شمس المركي لي

\section{المستخلس}

لبيان أهمية تصميم ألفا الثبكي كتصميم بديل لتصميم القطاعات الكامله العشوائيه في زيادة دقة تجارب مقارنة الاصناف فى محصول الفول البلدى فقد أجريت تجربتان حقليتان بمحطة بحوث الفوث الجيزه

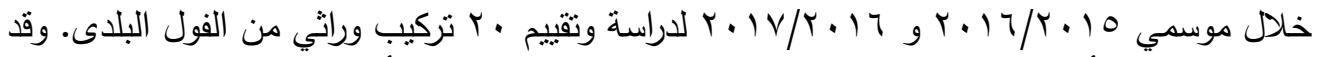

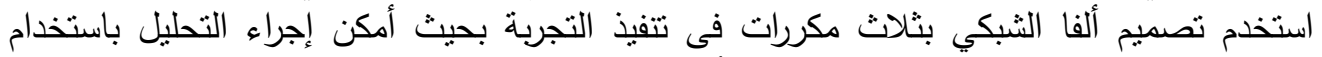
تصميم القطاعات العشوائية الكاملة و تصميم ألفا الثبكي المتبع.

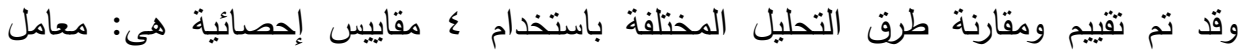
الاختلاف؛ الكفاءة النسبية؛ مستوى المعنوية؛ دالة القوفئ القوة.

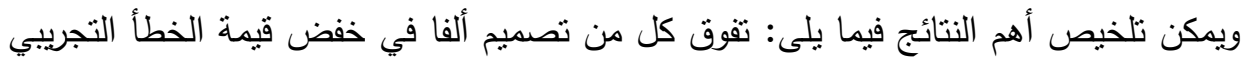

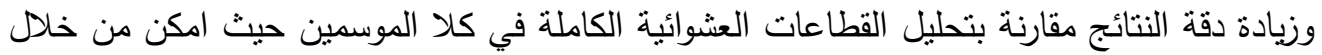

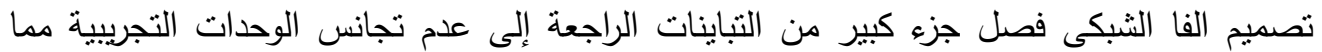

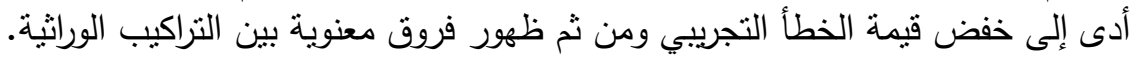

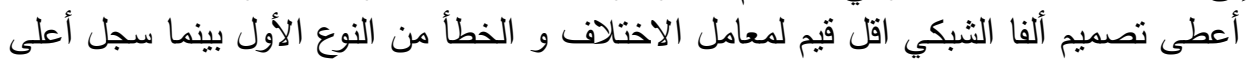
قيمه للكفاءة النسبية ودالة القوة مقارنة بالقطاعات العشوائية الكاملة.

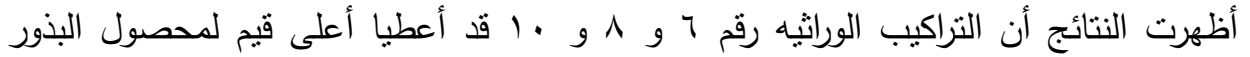

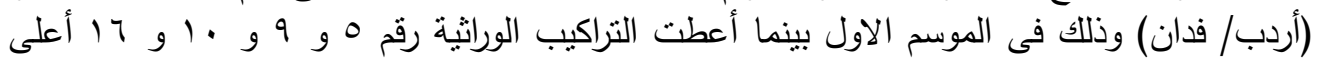

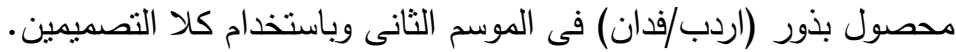
الكلمات الدالة: الفول البلدى، الفا الثبكى، الكفاءة النسبية، الدقة. 